\title{
Intravascular uplift of an occlusive spiral dissection using a hi-torque PILOT 150 guidewire for successful entry of the true right coronary artery lumen
}

\author{
Wewnątrznaczyniowe uniesienie spiralnej dyssekcji przy użyciu prowadnika \\ extra-hi-torque PILOT 150 w celu skutecznego osiągnięcia właściwego światła \\ prawej tętnicy wieńcowej
}

\author{
Mariusz A. Dębski ${ }^{1}$, Łukasz Kalińczuk ${ }^{1}$, Artur Dębski² ${ }^{2}$ Dariusz Karwowski ${ }^{3}$, Marcin Demkow $^{1}$ \\ 'Department of Coronary and Structural Heart Diseases, The Cardinal Stefan Wyszynski Institute of Cardiology, Warsaw, Poland \\ ${ }^{2}$ Department of Cardiology and Interventional Angiology, The Cardinal Stefan Wyszynski Institute of Cardiology, Warsaw, Poland \\ ${ }^{3}$ Department of Interventional Cardiology, The Joseph Psarski Mazovian Hospital, Ostroleka, Poland
}

A 78-year-old male with stable coronary artery disease and hypertension history was re-admitted for coronary angiography due to aggravated angina symptoms (CCS 3). In a coronary angiography performed six years earlier, plaque rupture with significant proximal right coronary artery (RCA) narrowing had been found (Fig. 1A, white arrow), and ad hoc percutaneous coronary intervention (PCI) had been attempted with 6.0 French Amplatz 2.0 Right Guide Catheter (Fig. 1A, asterisk). It had been unsuccessful, complicated with a spiral and occlusive dissection Type D of proximal and mid RCA and an aortic wall dissection (Fig. 1B, white and black arrows, respectively). According to The National Heart, Lung, and Blood Institute, Type D dissections represent spiral luminal filling defects, frequently with excessive contrast staining of the dissected false lumen ("barber shop pole", Fig. 1B, white arrows). Coronary computed tomography had confirmed the above. The patient had been qualified for conservative treatment. Currently first contrast injection with 5.0 Fr Judkins Right Diagnostic Catheter (Fig. 1B, hashtag) revealed normally patent RCA with a proximal narrowing, but smooth lumen view within the healed plaque rupture (Fig. 1C, white arrow). Interestingly, with the second injection, proximal wall dissection was discovered (Fig. 1D, E, black arrows). Well alienated true RCA lumen was preserved (Fig. 1E, yellow arrows) and thus $\mathrm{PCl}$ was attempted with 6.0 Fr Judkins 3.5 Right Guide Catheter. Whisper ES guidewire was gently manoeuvred, probing for the true RCA lumen and avoiding dissection increase. Despite several attempts, additional balloon catheter support, and overall gentle manoeuvres accompanied with angiographic control in optimal views, the guidewire seemed to negotiate a way through the true lumen but ultimately slipped into the subintimal space (Fig. 1E-H). As a result, TIMI flow decreased to 1 grade, with adequate patient's symptoms of ST elevation myocardial infarction. Thus, a Hi-Torque PILOT 150 guidewire was introduced into the proximal RCA and gently but firmly moved forward, surprisingly, resembling in its way the spiral pattern of the dissection (Fig. 11, zoom $2.5 \times$ ). Simultaneous, tender contrast injections confirmed restored distal RCA opacifications. At that time, Whisper ES was easily introduced in the central outline of RCA true lumen, being also the central outline of a unique "corkscrew figure"

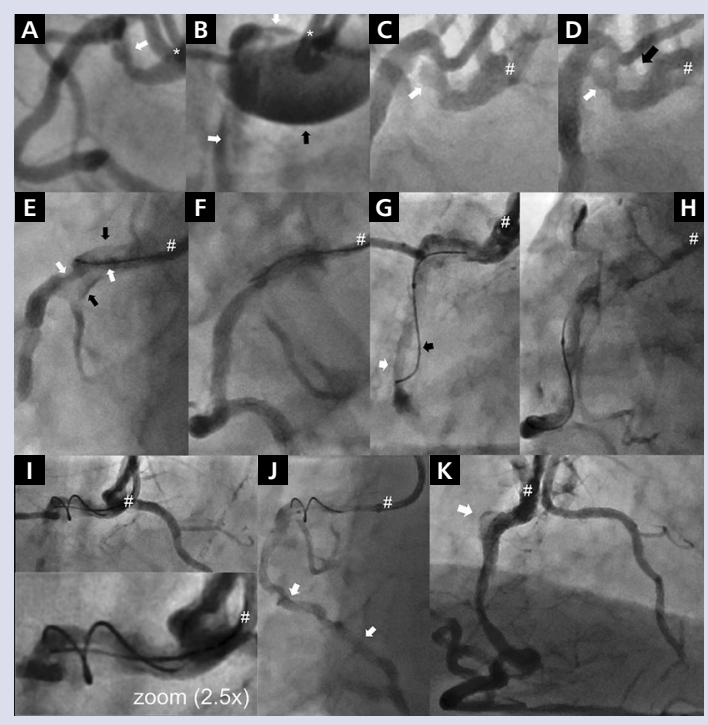
created with PILOT. Finally, it passed distally into the true RCA lumen (Fig. 11, J, white arrows). Presumably the higher tip load, as well as high torque transmission of PILOT, resulted in the successful uplift of the dissected artery wall, which was futile with Whisper. Finally, with prior predilatations, three drug-eluting stents (Xience 4.0/18 mm, 3.5/20 mm, 3.5/16 mm) were implanted, restoring TIMI 3 and MBG 3 epicardial flows. No residual stenosis was seen while deep coronary artery wall dissection was visualised behind the stents' struts (Fig. 1K, white arrow). Laboratory test abnormalities were confined only to slight troponin $\mathrm{T}$ level elevation. The approach presented above may prove to be useful in coronary artery dissection treatment.

Figure 1. A, C, D. Significant lesion in proximal right coronary artery (RCA) and dissection of the artery wall; $\mathbf{B}$. Well confined right sinus of Valsalva aortic wall dissection, in the region of the RCA ostium; E-H. Whisper ES guidewire in the subintimal space; I. PILOT 150 guide wire in a "cokrscrew" figure, uplifting the dissection and opening the artery true lumen; J. Whisper ES guide wire passed to the distal part of RCA true lumen; K. Final angiogram. Reconstructed RCA true lumen

Address for correspondence:

Mariusz A. Dębski, MD, Department of Coronary and Structural Heart Diseases, The Cardinal Stefan Wyszynski Institute of Cardiology, ul. Alpejska 42,

04-628 Warszawa, Poland, e-mail: mariuszarturdebski@gmail.com

Conflict of interest: none declared

Kardiologia Polska Copyright (c) Polskie Towarzystwo Kardiologiczne 2017 